\title{
PROPAGAÇÃo VEGETATIVA DO PESSEGUEIRO POR ALPORQUIA ${ }^{1}$
}

\author{
LUIS ANTÔNIO SUITA DE CASTRO² \& CARLOS AUGUSTO POSSER SILVEIRA ${ }^{3}$
}

RESUMO - A produção de mudas de frutíferas perenes está baseada na multiplicação vegetativa por manter as características da planta de origem. No pessegueiro, as mudas são obtidas por enxertia de gema ativa. Como não existem relatos de utilização da alporquia na multiplicação do pessegueiro, este trabalho teve como objetivo avaliar sua eficiência na propagação desta frutífera. O experimento foi realizado na Embrapa Clima Temperado, Pelotas-RS, nos meses de junho a setembro de 2001 com as cultivares Chirua e Maciel. A alporquia foi realizada em quatro épocas. As plantas, na época I (06-06), apresentavam-se dormentes. Nas demais épocas, apresentavam flores no estádio de balão ou abertas (épocas II e III - 26-06 e 16-07), enquanto, na época IV (08-08), possuíam brotações e frutos em desenvolvimento. Foi retirado um anel entre 1,0 e 1,5 centímetro de largura da casca de cada ramo com um canivete de enxertia. Em cada ferimento, foram colocadas quatro gotas do ácido indolbutírico (3000 mg.L $\left.\mathrm{L}^{-1}\right)$. Houve $100 \%$ de enraizamento. Em todos os ramos das duas cultivares, ocorreu a formação de raízes vigorosas e em grande número. Nas alporquias realizadas na época I, as raízes apresentaram maior ramificação. Os resultados foram satisfatórios, indicando que o método pode ser utilizado com sucesso no pessegueiro, principalmente em trabalhos de pesquisa que necessitem de um pequeno número de plantas idênticas geneticamente.

Termos para indexação: Propagação, enraizamento, mergulhia aérea; Prunus persica.

\section{VEGETATIVE PROPAGATION OF PEACH BY AIR LAYERING TECHNIQUE}

ABSTRACT - The propagation of fruit species is based on vegetative multiplication in order to maintain the characteristics of the original plant. The technique of air layering has been used in other species, however there is no report of its use in peaches trees. This work aimed to develop a methodology by using this technique in this species. The experiment took place in the period of June to September, 2001 at Embrapa - Clima Temperado, Pelotas, RS. The air layering technique was tested in four different periods using two cultivars: Chirua and Maciel. The plants used in the period I (06/06) were dormant. In all the order periods, the plants had flower buds, either at balloon stage or opened (periods II and III - 06/26 and 07/ 16), while in the period IV (08/08) they were already fruiting. The results indicated that this technique can be used in peach.

Index terms: Propagation, rooting, air layering; Prunus persica.

O Brasil produz 135.000 toneladas de pêssegos (Prunus persica L.) ao ano. Devido à abertura do mercado, à competitividade com produtos importados e à exigência crescente do consumidor, os persicultores brasileiros obrigam-se a buscar novas tecnologias.

A produção de mudas de plantas frutíferas está baseada na multiplicação vegetativa por assegurar a uniformidade genética dos indivíduos. A reprodução assexuada ocorre porque as células dessas plantas têm as informações genéticas necessárias para regenerar o organismo completo, fenômeno conhecido como totipotencialidade (Kerbauy, 1999). No pessegueiro, a produção de mudas é realizada, principalmente, por enxertia de gema ativa, nos meses de novembro a janeiro, sendo necessário um período variável entre 14 e 16 meses desde o plantio dos caroços. Outro método de propagação de prunóideas é o enraizamento de estacas (Trevisan et al., 2000; Nachtigal \& Pereira, 2000); no entanto, tem como inconveniente a necessidade de infra-estrutura adequada e de custo elevado (casa de vegetação com nebulização intermitente).

A multiplicação assexuada, denominada alporquia ou mergulhia aérea, tem sido utilizada na propagação de plantas, embora, não haja relatos para o pessegueiro. Tem-se registros em espécies como lichia e caju (Almeida et al., 1995), Ficus elastica (Hartmann \& Kester, 1990), mangueira e várias espécies de plantas ornamentais (Siqueira, 1998). De acordo com Browse (1979), a alporquia é uma das técnicas mais antigas de propagação vegetativa, utilizada na China há mais de mil anos. Também é denominada marcottage, nome que lembra a época da jardinagem francesa dos séculos XVII e XVIII. Como descrição do método, este autor recomenda que seja utilizado um ramo não podado, numa planta lenhosa, estimulado para o desenvolvimento de raízes, coberto acerca de 10-25 cm antes da gema apical, de maneira que a luz não atinja a porção revestida. Esta combinação de fatores provocará a formação de raízes, que prosseguirão o desenvolvimento se a referida parte estiver envolvida por terra úmida e aquecida. O ramo, posteriormente, é separado da planta-mãe, formando uma nova planta. De acordo com Siqueira (1998), o desenvolvimento das raízes é auxiliado por hormônios e pelo anelamento do ramo que impede que carboidratos, hormônios e outras substâncias produzidas pelas folhas e gemas sejam transladados para outras partes da planta. Por sua vez, o xilema não é afetado, fornecendo água e elementos minerais ao ramo. A alporquia tradicional utiliza como substrato o musgo esfagno, que é um produto desidratado, proveniente de plantas de gênero Sphagnum colhidas em pântanos, por ser leve, poroso e apresentar grande capacidade de retenção de água (10 a 20 vezes o peso original). Seu conteúdo em minerais é baixo e o $\mathrm{pH}$ varia de 3,5 a 4,0. Segundo Janick (1963), esse método de propagação é normalmente usado em plantas facilmente adaptadas a ele e naquelas que apresentam dificuldades de multiplicação.

Este trabalho teve como objetivo avaliar a eficiência da alporquia na propagação do pessegueiro. $\mathrm{O}$ experimento foi realizado na Embrapa Clima Temperado, Pelotas-RS, durante o período de junho a setembro de 2001. Foram utilizadas as cultivares de pessegueiro Chirua e Maciel. O processo de alporquia foi realizado em quatro épocas, iniciando durante o período de repouso vegetativo e estendendo-se até a fase de início de brotação e floração. No momento da escolha dos ramos, já havia sido feita a poda de inverno. As plantas correspondente à época I (06-06) apresentavam gemas floríferas e vegetativas em estado de dormência. Já nas demais épocas, a alporquia foi realizada em ramos que apresentavam flores abertas e também no estádio de balão (épocas II e III - 26-06 e 16-07, respectivamente), enquanto na época IV (08-08), todas as plantas apresentavam brotações em desenvolvimento, sendo que a cv. Maciel já apresentava frutos pequenos. Foram selecionados ramos lenhosos do último período vegetativo. A casca de cada ramo foi completamente removida com o auxílio de um canivete de enxertia, formando um anel com aproximadamente 1,0 - 1,5 centímetro de largura. Sobre cada ferimento, foram colocadas quatro gotas do ácido indolbutírico na concentração de $3000 \mathrm{mg} . \mathrm{L}^{-1}$. Posteriormente, os ramos foram introduzidos em tubos de filme de polietileno nas dimensões de 10 x $20 \mathrm{~cm}$ (saco plástico transparente com a extremidade inferior aberta). Após a amarração de uma das extremidades do tubo plástico ao ramo, abaixo do ferimento, este foi preenchido com vermiculita fina previamente umedecida. Finalmente, a extremidade superior do tubo também foi amarrada ao ramo, visando a criar um ambiente úmido e escuro ao redor da lesão.

\footnotetext{
' (Trabalho 181/2002). Recebido: 31/10/2002. Aceito para publicação: 30/07/2003. Desenvolvido com apoio financeiro do CNPq.

${ }^{2}$ M. Sc., Pesquisador da Embrapa Clima Temperado, BR 392 Km 78, CP 403, 96001-970, Fone: 0xx 53275 81 62, Pelotas - RS, Brasil E-mail: suita@cpact.embrapa.br.

${ }^{3}$ M. Sc., Bolsista DTI - CNPq, Embrapa Clima Temperado, BR 392 Km 78, CP 403, 96001-970, Pelotas - RS. E-mail: pos-ser@ig.com.br .
} 
Foram realizadas avaliações periódicas da superfície do substrato, para observar o surgimento de raízes ao redor do filme plástico, conforme constatado por Siqueira (1998). Após 112 dias do início do experimento (alporquias realizadas na época I), todos os alporques, das quatro épocas de ambas as cultivares, foram analisados. Nesta etapa, os alporques foram isolados da planta-mãe, o filme plástico foi retirado para avaliação das raízes e plantio em vasos plásticos com capacidade de 5 litros, contendo uma mistura de solo, areia e vermiculita (1:1:1), mantidos em condições de casa de vegetação com temperatura entre 18 e $25^{\circ} \mathrm{C}$.

O delineamento experimental foi em blocos casualizados, com 5 repetições, sendo cada parcela constituída de um alporque. O delineamento de tratamento foi um fatorial 2x4, sendo os fatores Cultivar (Maciel e Chirua) e Época (E1- 06-06; E2 - 26-06; E3 - 16-07; E4 - 08-08). As variáveis analisadas foram número de raízes (transformada segundo $\sqrt{x+1}$ ), e comprimento de raízes (em cm). A análise estatística dos dados foi feita através da análise da variação e decomposição da variação para os fatores Cultivar e Época, pela comparação de médias através do teste de Duncan $(\alpha=0,05)$. As análises estatísticas foram executadas pelo programa SANEST - Sistema de Análise Estatísticas para Microcomputadores (Zonta et al., 1984).

Em todos os ramos e em todas as quatro épocas, nas duas cultivares utilizadas, ocorreu a formação de raízes vigorosas e em grande número (Tabelas 1 e 2 e Figura 1B, 1C). Os alporques pertencentes à época I apresentaram raízes mais ramificadas (secundárias) que aqueles pertencentes às demais épocas, inclusive em relação à época II, embora o intervalo entre elas tenha sido de apenas vinte dias. Neste caso, também foi observado diferença de coloração das raízes. Na época I, estas apresentaram coloração marrom mais escura que nas demais épocas. Entretanto, devido ao sistema radicular estar em plena atividade, os ramos mostraram tonalidade amarelada das folhas, provavelmente devido à falta de nutrientes no substrato. Em avaliação final, realizada em 25 de setembro, por ocasião do transplante, observou-se que os alporques enraizados se diferenciaram quanto ao comprimento e número de raízes formadas. No entanto, tal diferença deve-se ao fato de que as alporquias foram feitas em épocas distintas, apresentando idades diferentes no momento da avaliação, conforme pode ser comprovado na Tabela 2. Apesar disso, observa-se que a cultivar Chirua apresentou tendência de aumento no número e no comprimento de raízes, de acordo com a época de realização da alporquia.

Os resultados permitem afirmar que este método de propagação apresenta vantagens em relação à estaquia, dentre as quais estão o alto percentual de enraizamento, a facilidade de propagação, independência de infra-estrutura (casa de vegetação com sistema de nebulização) e em relação à aclimatação (as mudas já estão adaptadas às condições ambientais). Esses fatores, aliados à necessidade de um pequeno núme- ro de mudas, conferem à alporquia a possibilidade de contribuir para a superação de alguns problemas de pesquisa, observados na propagação do pessegueiro. Os resultados obtidos foram altamente satisfatórios, indicando que a alporquia é uma técnica eficiente para a produção de mudas de pessegueiro, principalmente para trabalhos de pesquisa que necessitem de um pequeno número de plantas idênticas geneticamente (clones)

TABELA 1 - Avaliação do enraizamento dos ramos alporqueados de pessegueiro (Cvs. Chirua e Maciel) em 31-08-2001. Embrapa Clima Temperado, 2001.

\begin{tabular}{cccc}
\hline Épocas & $\begin{array}{c}\text { Data da } \\
\text { alporquia }\end{array}$ & $\begin{array}{c}\text { Dias } \\
\text { transcorridos }\end{array}$ & $\begin{array}{c}\text { Enraizamento } \\
(\%)\end{array}$ \\
\hline I & $06-06$ & 86 & 100 \\
II & $26-06$ & 66 & 100 \\
III & $16-07$ & 46 & 100 \\
IV & $08-08$ & 23 & 100 \\
\hline
\end{tabular}

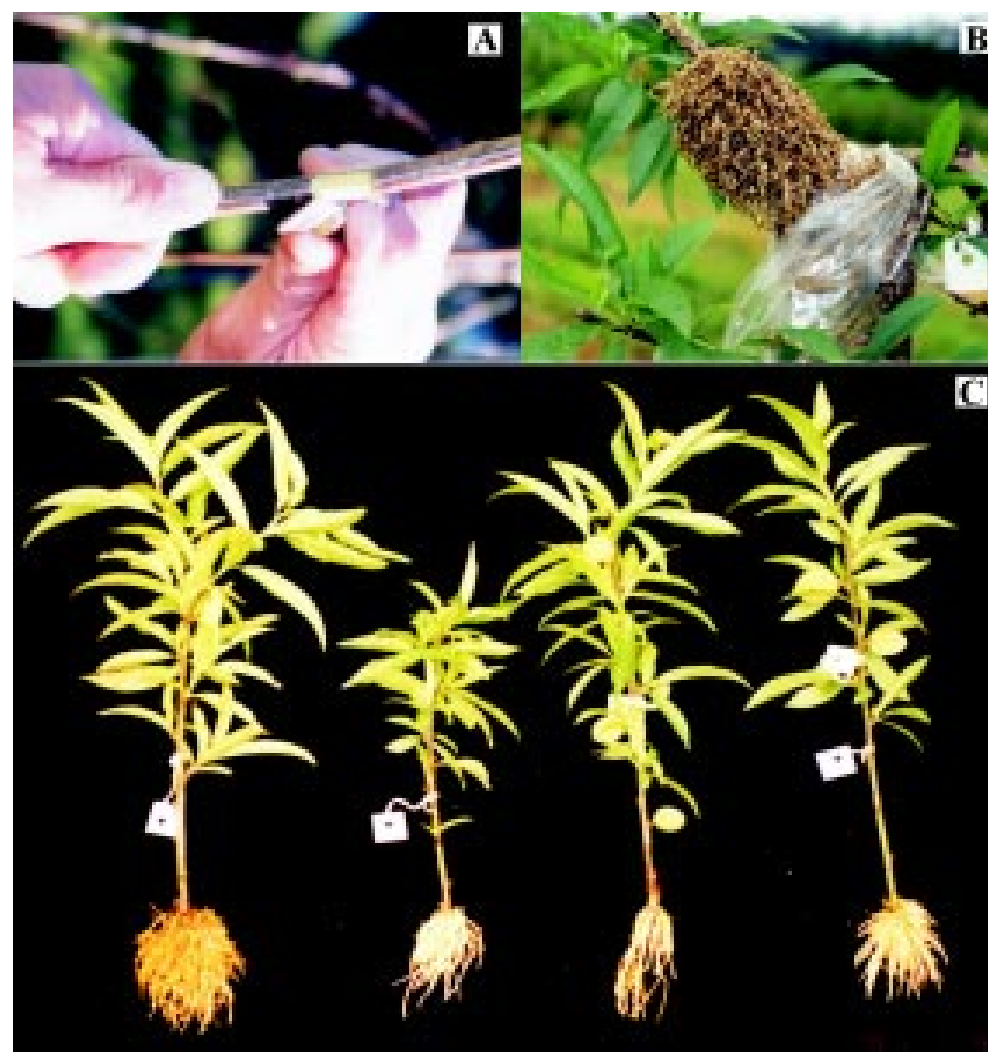

FIGURA 1 - Etapas da alporquia: (A) Anelamento do ramo de pessegueiro; (B) Retirada do tubo de polietileno; (C) Alporques separados da planta-mãe coletados, respectivamente, aos $115 ; 95 ; 71$ e 48 dias do anelamento dos ramos (observar a presença de frutos em desenvolvimento).

TABELA 2 - Número e comprimento médios das raízes de ramos alporqueados de pessegueiro (Cvs. Chirua e Maciel) em 25-09-200. Embrapa Clima Temperado, 2001.

\begin{tabular}{|c|c|c|c|c|c|}
\hline \multirow[t]{3}{*}{ Épocas } & \multirow{3}{*}{$\begin{array}{c}\mathrm{N}^{\mathrm{o}} \text { de dias até a } \\
\text { avaliação final (25-09) }\end{array}$} & \multicolumn{4}{|c|}{ Variáveis respostas } \\
\hline & & \multicolumn{2}{|c|}{$\mathrm{N}^{\circ}$ de raízes } & \multicolumn{2}{|c|}{ Comprimento de raízes } \\
\hline & & Maciel & Chirua & Maciel & Chirua \\
\hline $\mathrm{I}-06-06$ & 115 & $30,6 \mathrm{a} \quad \mathrm{C}$ & $15,6 \mathrm{~b} \quad \mathrm{D}$ & 6,0 a $A$ & $3,7 \mathrm{~b}$ \\
\hline II $-26-06$ & 95 & $40,6 \mathrm{~b} \quad \mathrm{~B}$ & 43,6 a $\mathrm{B}$ & $2,8 \mathrm{~b} \quad \mathrm{~B}$ & 5,8 a $\mathrm{AB}$ \\
\hline III $-16-07$ & 71 & 55,7 a $A$ & $37,0 \mathrm{~b} \quad \mathrm{C}$ & $3,2 \mathrm{~b} \quad \mathrm{~B}$ & 5,0 a $\mathrm{BC}$ \\
\hline IV $-08-08$ & 48 & $40,7 \mathrm{~b} \quad \mathrm{~B}$ & 64,0 a A & $4,5 \mathrm{~b} \mathrm{~A}$ & 7,0 a $\mathrm{A}$ \\
\hline
\end{tabular}

Médias seguidas de mesma letra minúscula, nas linhas, e maiúscula, nas colunas, não diferem entre si, pelo teste de Duncan $(\alpha=0,05)$. 


\section{REFERÊNCIAS BIBLIOGRÁFICAS}

ALMEIDA, F.A.G.; ALMEIDA, F.C.G.; MENEZES JUNIOR, J.; CARVALHO, P.R Estudo do sistema radicular de plantas de cajueiro-anão (Anacardium occidentale L.) obtidas por alporquia. Revista Brasileira de Fruticultura, Cruz das Almas, v.17, n.1, p.43-56, 1995.

BROWSE, P.M. A propagação das plantas. 3.ed. Lisboa: Publicações Europa-América, 1979. p.139-141.

HARTMANN, H.T.; KESTER, D.E. Propagación de plantas: principios y praticas. Ciudad del Mexico: Continental, 1990. 810p.

JANICK, J. Horticultural science. San Francisco: W.H. Freeman and Company, 1963.472p.

KERBAUY, G.B. Competência e determinação celular em culturas de células e tecidos. In: TORRES, A. C., CALDAS, L. S.; BUSO, J. A. (Ed.) Cultura de tecidos e transformação genética de plantas. Brasília:
Embrapa-SPI. v. 2, p. 519-531, 1999.

LUCCHESI, A.A. Propagação de plantas através da alporquia. Piracicaba: Universidade de São Paulo, ESALQ, 1993. 8p.

NACHTIGAL, J.C.; PEREIRA, F.M. Propagação do pessegueiro (Prunus persica L. Batsch) cv. Okinawa por meio de estacas herbáceas em câmara de nebulização em Jaboticabal - SP. Revista Brasileira de Fruticultura, Jaboticabal, v.22, n.2, p.208-212, 2000.

SIQUEIRA, D.L. de. Produção de mudas frutíferas. Viçosa: CPT, 1998. $74 p$.

TREVISAN, R.; SCHWARTZ, E.; KERSTEN, E. Capacidade de enraizamento de estacas de ramos de pessegueiro (Prunus persica L. Batsch) de diferentes cultivares. Revista Científica Rural, Bagé, v.5, n.1, p.29-33, 2000.

ZONTA, E. P.; MACHADO, A. A. SANEST: sistema de análises estatísticas para microcomputadores. Pelotas-UFPel, 1984. 75p. 